\title{
Sofrimento acadêmico e violência epistêmica: considerações iniciais sobre dores vividas em trajetórias acadêmicas indígenas
}

\author{
Academic suffering and epistemic violence: initial \\ considerations on pain experienced in indigenous \\ academic trajectories
}

\author{
Alexandre Ferraz Herbetta ${ }^{1}$ \\ Elias Nazareno ${ }^{1}$
}

DOI: http://dx.doi.org/ 10.20435/tellus.v20i41.640

\begin{abstract}
Resumo: O objetivo deste texto é ressaltar a importância do tratamento do sofrimento psíquico em discentes pertencentes a populações indígenas em suas trajetórias acadêmicas na Universidade Federal de Goiás (UFG). Para tanto, foram realizadas análises a partir da experiência vivenciada por parte dos estudantes indígenas no curso de Educação Intercultural e nos demais cursos de graduação e pós-graduação da UFG. Na última década, tais contingentes populacionais têm acessado cada vez mais a academia, onde antes eram apenas excluídos. Desta forma, para que suas trajetórias acadêmicas, importantes para eles, suas comunidades, a universidade e o país, concluam-se com bemestar e saúde, torna-se fundamental explorar todos os aspectos das políticas de permanência na universidade, como o sofrimento psíquico. Tendo em vista as abordagens presentes nos referenciais teóricos e metodológicos do grupo modernidade/colonialidade/decolonialidade, a hipótese presente em nosso estudo é de que há uma relação direta entre o sofrimento psíquico e a violência epistêmica.
\end{abstract}

Palavras-chave: estudantes indígenas; sofrimento; universidade; políticas educacionais.

\begin{abstract}
The aim of this paper is to emphasize the importance of treating the psychological suffering of students belonging to indigenous populations in their academic trajectories at the Federal University of Goiás (UFG). We analyze experiences of indigenous students in the Intercultural Education Course and other undergraduate and postgraduate courses at UFG. In the last decade, such population contingents have increasingly accessed the academy, where
\end{abstract}

${ }^{1}$ Universidade Federal de Goiás (UFG), Goiânia, Goiás, Brasil. 
they were previously only excluded. Thus, for their academic trajectories, important for them, their communities, the university and the country, to be completed with well-being and health, it is essential to explore all aspects of permanence policies in university, such as psychological suffering. Given the approaches present in the theoretical and methodological frameworks of the group modernity/coloniality/decoloniality, the hypothesis present in our study is that there is a direct relationship between psychological suffering and epistemic violence.

Keywords: indigenous students; suffering; university; educational policies.

\section{INTRODUÇÃO}

Desde 2003, especialmente por meio de políticas de ação afirmativa, o número de estudantes indígenas tem crescido de forma exponencial nas universidades públicas brasileiras. Com base em levantamentos do Centro Indígena de Estudos e Pesquisa, Cruz (2017) afirma que, em 2010, havia no Brasil aproximadamente 6 mil estudantes indígenas no Ensino Superior e ao menos 100 deles estavam matriculados em programas de pós-graduação. Ainda segundo Souza Lima (apud CRUZ, 2017, p. 95), em 2016, esse número saltou para mais de 10 mil estudantes em universidades públicas e particulares.

Esses dados demográficos apontam para um percentual de estudantes indígenas no Ensino Superior maior do que 10\% do total da população indígena brasileira, que corresponde a 896.917 indivíduos, o que equivale a 0,47\% da população total do país (INSTITUTO BRASILEIRO DE GEOGRAFIA E ESTATÍSTICA [IBGE], 2010). Na Universidade Federal de Goiás (UFG), contamos com cerca de 400 estudantes indígenas no nível de graduação. Estes se dividem em cursos variados das áreas de Exatas, Humanas e Biológicas (cerca de 100 alunos). E também no curso específico de Educação Intercultural (cerca de 300 alunos). Conta-se igualmente com cerca de 15 indígenas em nível de pós-graduação (mestrado e doutorado). Neste caso, destaca-se o Programa de Pós-Graduação em Antropologia Social, que possui 12 indígenas entre mestrado e doutorado.

O acesso dos estudantes indígenas à universidade se deu, em linhas gerais, pelos seguintes caminhos: por meio da Lei de Cotas e graças à criação dos cursos de Licenciatura Intercultural Indígena, voltados para a formação de professores indígenas - ambos dão acesso a cursos de graduação; e por políticas específicas 
Sofrimento acadêmico e violência epistêmica: considerações iniciais sobre dores vividas em trajetórias acadêmicas indígenas

para o acesso à pós-graduação. Na UFG, esses caminhos se efetivam por meio do Programa UFGInclui, vinculado à Pró-Reitoria de Graduação (PROGRAD), com início no concurso vestibular de 2009/1 e que se relaciona à política de cotas. Em segundo lugar, por meio da Resolução Consuni n. 07/2015, que dispõe sobre a política de ações afirmativas para pretos, pardos e indígenas na Pós-Graduação stricto sensu na UFG. E, em seguida, por meio do Núcleo Takinahakỹ de Formação Superior Indígena, vinculado à Faculdade de Letras (FL), com início em 2007 e que abrange também o Curso de Educação Intercultural, voltado à formação em nível superior de docentes indígenas.

Neste cenário acadêmico, há indígenas de 27 populações distintas do país. Entre elas, Krahô, Apinajé, Tapirapé, Kamayurá, Waurá, Canela, Gavião, Xavante, Xerente, Krikati, Xacriabá, Guarani, Karajá, Xambioá, Kayabi, Mehinako, Juruna. Seus locais de origem se encontram em cinco estados da Federação: Goiás, Tocantins, Maranhão, Mato Grosso e Minas Gerais. Há também cerca de 100 egressos do Curso de Licenciatura Intercultural Indígena atuando em suas comunidades e regiões, bem como dois mestres formados, um Xerente no programa de Pós-Graduação em Direitos Humanos (PPGDH) e uma Krahô no Programa de Pós-Graduação em Antropologia Social (PPGAS).

Letícia Jokakwyj Krahô (2019, p. 29), por exemplo, mestra e doutoranda do Programa de Pós-Graduação em Antropologia Social (PPGAS) da UFG, afirma:

[...] quero seguir o exemplo das mulheres de minha família, ser uma contadora de nossas histórias. Faço parte de uma família de mulheres muito fortes e de grande influência para e nas nossas comunidades. Tento nesse trabalho trazer um pouco da pesquisa que fiz com minha mãe, minha avó e minha bisavó, refletindo sobre as várias maneiras de ensinar, de aprender e de conhecer as coisas do mundo. Por meio das conversas com meus parentes, pretendo criar minha própria narrativa, entrelaçando à de minhas parentas mulheres-cabaças, entendendo a construção desta narrativa como um meio de problematização da circulação de conhecimentos entre meu povo e refletir sobre o potencial da escola atualmente.

Esses dados apontam igualmente para uma realidade bastante complexa que ainda começa apenas a ser desvelada por pesquisas acadêmicas sobre o tema das populações indígenas em trajetória acadêmica na universidade. Tais pesquisas mostram-se fundamentais para a formulação das novas políticas de 
inclusão e permanência. Elas apontam em termos quantitativos para um aumento considerável na inclusão de indígenas nas universidades brasileiras; não revelam, entretanto, o outro lado do problema, que é o da permanência, que quando não se dá produz fracasso escolar e evasão desses estudantes, rompendo suas trajetórias acadêmicas e gerando sofrimento psíquico nos sujeitos.

Para a intelectual quilombola Marta Quintiliano (2019, p. 10), doutoranda no PPGAS/UFG, em relação à pós-graduação,

Na entrada há, por exemplo: taxa de inscrição, a exigência da obrigatoriedade de uma língua indo-europeia, o preenchimento da plataforma Lattes, que não permite muitas vezes a inserção dos nomes dos candidatos indígenas, a bibliografia extensa e desconectada da realidade dos alunos cotistas. Para aqueles candidatos que conseguem ultrapassar as barreiras da exclusão na entrada, ficam outros problemas como, por exemplo: a permanência e a saída.

No mesmo sentido, segundo Tassinari, em relação à alta evasão de estudantes indígenas cotistas na Universidade Federal de Santa Catarina,

Quanto aos motivos de evasão, são relatados: dificuldade para pagar o transporte da aldeia até a universidade; impossibilidade de conciliar trabalho e estudos (principalmente no caso dos estudantes casados e com filhos); saudades da família; e sentimento de solidão na vida universitária e urbana [...] Muitas das entrevistas apontam também para as "circunstâncias desagradáveis" vivenciadas pelos estudantes na sala de aula, especialmente relativas ao questionamento da sua condição de indígenas [...] Além de serem constantemente cobrados a provar sua condição de indígenas, os estudantes relatam que muitas vezes se sentem excluídos dos círculos de amizade e às vezes vivenciam situações de hostilidade explícita. (TASSINARI, 2016, p. 48)

Esse aparente paradoxo entre acesso e permanência dos estudantes indígenas nas Instituições de Ensino Superior (IESs) brasileiras tem explicações bastante complexas que estão em grande parte relacionadas aos processos de colonialidade do poder, do ser e do saber. Tais processos, ao racializarem as diferenças, reservaram a estas populações, suas línguas e seus conhecimentos um violento processo de subalternização e invisibilização.

No caso indígena, o intelectual Daniel Munduruku (2017) já afirmava:

[...] basta lembrar, para isso, que o domínio da escrita do pariwat é justificado pela necessidade de ler a realidade brasileira que, a priori, não faz 
parte do imaginário indígena. De modo que, a meu ver, foi-se criando uma necessidade nos jovens nativos de apreender conceitos e teorias que não cabem no pensar holístico e circular de seus povos. Esta agressão ao sistema mental indígena, fruto de uma história da qual não somos culpados, mas sobre qual temos responsabilidade, acaba se perpetuando nas novas políticas inclusivistas levados [sic] a efeito por governos nas três esferas. Conclusão: nossos jovens se vêm [sic] obrigados a aceitar como inevitável à [sic] necessidade de ler e escrever códigos das [sic] quais prefeririam não aprender e não lhes é dado o direito de recusar sob a acusação de preguiça ou descaso para com a "boa vontade" dos governos e governantes.

Isto se dá claramente, portanto, quando as dinâmicas universitárias não compreendem as formas próprias de cognição e cosmovisão destes povos. No caso aqui tratado, a violência epistêmica acontece quando não se consideram os modos próprios de subjetivação presentes nas diversas ontologias indígenas.

Neste sentido, para Daiara Sampaio Tukano (2018, p. 18),

Na perspectiva do direito à memória e verdade como direitos humanos, os direitos à integridade psíquica e moral dos indivíduos tornam-se cerne dos direitos complementares que constituem o direito à identidade, uma vez que a identidade pressupõe o passado histórico da pessoa plena. O direito à história, à memória e à verdade pode se considerar preservado quando houver livre acesso e disponibilidade aos documentos e registros que o revelam, priorizando as narrativas de seus sujeitos, respeitando e acolhendo suas práticas de fazer, pensar e construir pensamento e política: garantir o direito de conhecimento do passado e o meio pelo qual o direito atua no presente para garantir que os membros de certa comunidade jurídica, no caso os povos indígenas, não tenham mais que suportar violações a suas integridades físicas, culturais, psicológicas e morais.

Como demonstram diversos estudos sobre o tema, o acesso por si só, sem o acompanhamento de medidas protetivas que garantam a permanência dos estudantes indígenas, não é garantia de nada (AMARAL; BAIBICH-FARIA, 2012; BERGAMASCHI; DOEBBER; BRITO, 2018; HERBETTA, 2018). Segundo o intelectual indígena Felipe Sotto Maior Cruz, por exemplo, pertencente ao povo Tuxá da Bahia, doutorando do Programa de Pós-Graduação em Antropologia Social (PPGAS) da Universidade de Brasília, "Existe uma ideologia em torno da presença indígena nas universidades que fala da diversidade e da pluralidade como algo alcançável meramente com o acesso" (CRUZ, 2017, p. 96). 
Na mesma direção, Ercivaldo Damsokekwa (2015), doutorando no PPGASUFG, corrobora o exposto.

Como pertencente a um grupo étnico indígena de um país que viveu uma experiência colonial, trago guardado na memória um legado cultural contado pelos antepassados, marcado por uma história de colonização, perseguição, massacres e segregação, assimilação e controle tutelar. Mais recentemente, mesmo as gerações mais jovens viveram e vivem essa segregação no que se refere aos direitos que são destinados à população brasileira de modo geral. Muitas das perdas culturais, como as muitas línguas indígenas e os conhecimentos tradicionais que foram perdidos nesse processo são como resultados da desvalorização e invisibilização das culturas indígenas do país, são irreversíveis.

Letícia Krahô (2019, p. 39), doutoranda do mesmo PPGAS, fundamenta o exposto. Ela afirma sobre o início da graduação:

Assim que ingressei na UFT, me deparei com muitos obstáculos e dificuldades. Primeiro tive que me adaptar ao local longe de minha família, da minha cultura, o modo de vida era diferente, muito barulho na cidade, você anda com medo na cidade, todo um conjunto que não fazia parte do meu convívio. Na faculdade todas as disciplinas eram difíceis, teorias complexas, pois o português é minha segunda língua.

Neste contexto, a cada ano percebemos no ambiente acadêmico, como docentes da UFG, onde lecionamos, mais situações que apontam para o adoecimento entre discentes da graduação e pós-graduação da instituição. Tais casos se dão especialmente entre populações indígenas, negras e negras quilombolas, como também entre populações de ascendência europeia. Em relação aos indígenas, além de tudo, o sofrimento psíquico se dá em alto grau por conta do desrespeito a seus modos próprios de subjetivação.

Para Santos (1989, p. 11),

[...] muitas vezes a universidade não parece preparada para defrontar os desafios, tanto mais que estes apontam para transformações profundas e não para simples reformas parcelares. Aliás, tal impreparação, mais do que conjuntural, parece ser estrutural, na medida em que a perenidade da Instituição Universitária, sobretudo no mundo ocidental, está associada à rigidez funcional e organizacional, à relativa impermeabilidade, às pressões externas, enfim, à aversão à mudança. 
Sofrimento acadêmico e violência epistêmica: considerações iniciais sobre dores vividas em trajetórias acadêmicas indígenas

Estas situações apresentam-se concretamente em diversas formas: um mestrando que não consegue finalizar a escrita de sua dissertação e perde todos os prazos do programa, sendo excluído dele; graduandos que abusam regularmente do álcool, perdendo todas suas atividades acadêmicas; um doutorando que não consegue passar pelo exame de qualificação; um mestrando que adoece gravemente e abandona os estudos, entre muitos outros casos. Há, até mesmo, casos de tentativas de suicídio.

Neste contexto, Pechincha (2018, p. 223) diz:

Conforme pude apreender em pesquisa bibliográfica, existe considerável número de estudos publicados acerca de suicídios entre coletivos indígenas ao redor do mundo, a maioria de autoria de pesquisadores ligados aos campos da psiquiatria, da psicologia e, em muito menor número, da antropologia. Nota-se, igualmente, que o volume desses estudos aumenta na proporção direta da identificação do problema como crescente em décadas recentes. De qualquer forma, as taxas levantadas entre os povos indígenas são de índices proporcionalmente multiplicados em relação a seus vizinhos não indígenas no mesmo país.

Em todas as situações, o sofrimento psíquico é base das ações. Segundo Andrade et al., que se debruçou em pesquisa sobre o sofrimento psíquico entre estudantes de Psicologia, "De uma forma geral, os estudos apresentados nessa seção apontam diversas manifestações associadas ao sofrimento psíquico, desde a dependência química e os sintomas psicossomáticos até o absenteísmo e a evasão" (ANDRADE et al., 2016, p. 834).

Tais situações se apresentam ainda em todas as etapas da vida acadêmica e causam desconforto em todos os sujeitos que participam do processo, técnicos administrativos, discentes e docentes. Para Cerchiari et al. e Neves e Dalgalarrondo (apud ANDRADE et al., 2016, p. 833),

No Brasil, em universidades públicas, os índices de prevalência de TMM [Transtornos Mentais Menores] variaram entre 25\% (Cerchiari et al., 2005a) e 58\% (Neves, \& Dalgalarrondo, 2007). Nos questionários de rastreamento, os principais sintomas investigados são os níveis de estresse, distúrbios psicossomáticos, irritabilidade, fadiga e insônia, entre outros possíveis.

Muitos destes casos acabam produzindo casos de depressão e causam impactos profundos na vida das pessoas em referência, arriscando inclusive suas 
vidas. Todos os casos afetam sobremaneira a trajetória acadêmica destes estudantes, muitas destas trajetórias, inclusive, são deixadas de lado, gerando sentimento de fracasso no discente e na universidade e mascarando as potencialidades das políticas de ação afirmativa.

Apesar da gravidade, tal situação ainda é pouco documentada. Para Andrade et al. (2016, p. 832), há "demanda por serviços de atendimento psicológico com vistas a minimizar o sofrimento psíquico destes alunos". O autor destaca ainda "a gravidade da questão que, a despeito da justificativa de situação de crise, não pode ser descuidada ou ter as providências a respeito adiadas" (ANDRADE et al., 2016, p. 832).

Neste contexto, a pesquisa aqui apresentada, que se relaciona ao projeto "Atualizando e esticando a universidade: considerações sobre a possibilidade de uma pluriversidade", cadastrado na Universidade Federal de Goiás e realizado especialmente na Faculdade de Ciências Sociais, desenvolvendo-se há 5 anos, busca registrar, por meio da leitura de bibliografia indígena e não indígena sobre o tema e por meio de observação participante e da perspectiva da não metodologia indisciplinada, que subverte "a relação de objetivação/subjetivação, a linearidade temporal da sequência de produção de conhecimento, a distribuição topológica do conhecimento teórico e do mundo, e a autonomia prática do conhecimento a respeito das relações social/vitais" (HABER, 2011, p. 17, tradução do autor), a grave e ignorada situação acadêmica do sofrimento psíquico em populações indígenas em trajetória acadêmica na UFG, apontando para a proposição de políticas efetivas de inclusão e permanência nesta universidade e em outras.

Nossa hipótese é de que a estrutura universitária atual, majoritariamente, tem sua base lógica centrada em uma matriz monocultural, logocêntrica e europeia, que, consequentemente, se efetiva por meio de processos nomeados como colonialidade do ser, do saber e do poder. Esta lógica impõe dinâmicas de violência epistêmica, especialmente às populações indígenas, as quais têm como centro a invisibilização, a subalternização e a eliminação de outros modos de subjetivação. Note-se que a subjetivação de populações indígenas vem sendo tratada na literatura etnológica e é marcantemente diferente da formação da psique ocidental.

Este descompasso é a base de um processo de sofrimento psíquico. 


\section{ASPECTOS METODOLÓGICOS}

O tema a despeito de sua relevância é bastante novo nas discussões sobre o acesso e a permanência de populações indígenas na universidade. Neste contexto, vale lembrar que

Apesar de a universidade pública brasileira ser um dos poucos redutos de exercício do pensamento crítico em nosso país, se a observamos a partir da perspectiva da justiça racial impressiona a indiferença e o desconhecimento do mundo acadêmico a respeito da exclusão racial com que, desde sua origem, convive. Desde a formação das instituições de ensino superior no século dezenove, não houve jamais um projeto, nenhuma discussão sobre a composição da elite que se diplomaria nas Faculdades de Direito, Medicina, Farmácia e Engenharia existentes naquela época. (CARVALHO; SEGATO, 2002, p. 5)

Neste cenário, poucos autores discutem profundamente e de maneira complexa as dinâmicas próprias e impactos das políticas de ação afirmativa no país. Ressalta-se, assim, a necessidade de aprofundamento qualitativo da questão, neste caso, por meio de uma análise da relação entre sofrimento psíquico e colonialidade.

Considerando o fato de que boa parte dos estudos sobre as políticas de ação afirmativa implementadas no país advém de metodologias mais quantitativas (não apenas), as quais evidenciam o considerável incremento demográfico no acesso de populações indígenas, negras e negras quilombolas no Ensino Superior e seus impactos positivos e negativos, como o desempenho cotista nos programas e cursos; as perspectivas baseadas nas novas relações sociais estabelecidas entre os sujeitos e suas situações de superação e, também, discriminação; e a luta política realizada por agentes acadêmicos para o avanço destas políticas, entre outras, busca-se aqui enfocar um aspecto mais qualitativo, centrando-se na questão do sofrimento psíquico de estudantes indígenas em trajetória acadêmica.

Desta feita, em primeiro lugar, propõe-se proceder a uma leitura de literatura produzida por intelectuais indígenas (e quilombolas), especialmente a partir da década de 2000. Em determinada medida, a despeito de tratarem de outros temas, como políticas de reparação social, narrativas indígenas, escolarização e redes de solidariedade, muitas destas pesquisas falam claramente e diretamente sobre processos de sofrimento, adoecimento e cura. 
O trabalho de Quintiliano e Jokakwyj, por exemplo, apresentado no Grupo de Trabalho Negros, Indígenas e Quilombolas na Universidade: Direitos, Demandas e Desafios à Construção da Educação Pluriepistêmica, no IV Simpósio da Faculdade de Ciências Sociais - Democracia e Direitos Humanos: Crises e Conquistas, realizado no dia 11 de setembro de 2019, na Universidade Federal de Goiás, Campus Samambaia, na cidade de Goiânia, é intitulado "Epistemologias que Curam". Nesta pesquisa, apresentam práticas de suas matrizes culturais que podem ser realizadas no espaço acadêmico e que, tendo como foco o corpo, podem curar.

Em seguida, em especial, por meio da observação participante, apresenta-se uma sistematização de programas, ações e espaços constituídos na instituição universitária em referência que sejam relevantes no processo de implementação de políticas de acesso e permanência de populações indígenas na universidade.

Trata-se de ações relacionadas especialmente ao programa UFGInclui, vinculado à PROGRAD, com início no concurso vestibular de 2009/1 e que se relaciona à política de cotas; à participação na criação e instauração da Resolução Consuni n. 07/2015, que dispõe sobre a política de ações afirmativas para pretos, pardos e indígenas na Pós-Graduação stricto sensu na UFG; e a uma atuação intensa, desde 2011, no Núcleo Takinahakỹ de Formação Superior Indígena, vinculado à Faculdade de Letras (FL), com início em 2007 e que abrange também o Curso de Educação Intercultural, voltado à formação em nível superior de docentes indígenas.

A atuação em diversos graus nestes processos fundamentais para a implementação de políticas de inclusão e permanência na UFG nos faz estar presentes em diversos e inumeráveis momentos de conversa, debates e produção acadêmica, como nos Seminários de Educação Intercultural realizados todos os sábados nas Etapas de Estudos em Goiânia do curso de Educação Intercultural Indígena, que se dá entre janeiro e fevereiro e julho e agosto, sendo componentes obrigatórios da dinâmica do referido núcleo, entre inúmeros outros.

Vale ressaltar que, para além da observação participante, propõe-se aqui uma reflexão em conjunto com parte das populações indígenas presentes na comunidade universitária, por meio da metodologia da composição (COLECTIVO SITUACIONES, 2002; HABER, 2011) baseada em fluxos de conversas com os agentes atuantes no processo em tela. Haber (2011, p. 24) diz: 
[...] refiro-me à conversa como um fluxo de agenciamentos intersubjetivos que cria subjetividades em relação; estas que não são cortadas pela troca linguística nem pela humanidade dos que interagem, mas pelo contrário, não se está em conversação na qualidade acabada de falante, mas sim, como sendo ou melhor, se participa do processo no "estar sendo". (tradução do autor)

Para Chilisa (2012, p. 91), de outra forma "a produção de conhecimento continua trabalhando dentro da estrutura colonizador/colonizado". A proposta, assim, importante comentar, não é a de apenas substituir o termo entrevista por conversa, apontando para algum pseudoplano de pesquisa alternativo, "e não se trata aqui de objetificar o sujeito objetificante, tal como propôs P. Bourdieu (1988) como único antídoto ao objetivismo" (HABER, 2011, p. 18, tradução do autor).

Entende-se que

[...] as relações de solidariedade são estabelecidas ao longo do tempo e exigem responsabilidades, compromissos e apoio, mas acima de tudo, afetos trans ou intersubjetivos. As relações de conversação também são estabelecidas no tempo, elas acontecem entre aqueles que falam, assim como estes se transformam na conversação. As conversações com os sujeitos e coletivos populares, movimentos sociais e comunidades locais, enfim, junto àqueles com quem se formam solidariedades duradouras nas quais nos reconhecemos mutualmente, são a situação da investigação. (HABER, 2011, p. 23, tradução do autor)

A conversação permite relações mais afetuosas e respeitosas, possibilita o afastamento das hierarquizações presentes nas típicas relações acadêmicas de poder professor/estudante, além de romper com a dicotomia conhecimento hegemônico e saberes subalternos.

\section{POLÍTICAS ACADÊMICAS PARA AMENIZAR O SOFRIMENTO}

Para Quintiliano (2019, p. 17)

[...] as dificuldades de permanecer no espaço acadêmico que a cada minuto te expurga de maneira agressiva ou, em outras situações, te expele por mecanismos bem sutis são diversas. São inúmeras as estratégias de exclusão, que vão desde o racismo institucional, violências psicológicas, epistemicídio, adicionados à falta de ajuda financeira e familiar. 
Esta grave situação indica que há necessidade urgente de haver serviços que tratem do sofrimento psíquico no espaço acadêmico. Cerchiari, Caetano e Faccenda (2005b apud ANDRADE et al., 2016, p. 835) afirmam:

[...] encontramos que esse tipo de serviço teria surgido nos Estados Unidos no início do século XX, a partir do reconhecimento de que os universitários passam por uma fase vulnerável, do ponto de vista psicológico, e que, dessa forma, a responsabilidade em ajudá-los, nesse momento, seria da instituição em que se encontrem inseridos. Este reconhecimento levou à Primeira Conferência Internacional sobre Saúde Mental Estudantil, da qual participaram 37 especialistas de diferentes categorias profissionais, oriundos de vários países.

Parece-nos que no Brasil o assunto, de maneira geral, sempre é deixado de lado, seja por conta de seguidas crises econômicas e de corte de recursos, seja por um foco excessivo na produção científica acadêmica, com o objetivo de se tornar rapidamente um grande produtor mundial de ciência, seja por descaso com o tema, considerado em um contexto de valorização da meritocracia e ignorância sobre o sofrimento psíquico.

Para Andrade et al. (2016, p. 835),

[...] no que concerne ao Brasil, os autores situam como marco inicial do atendimento em saúde mental a universitários a criação, no ano de 1957, na Faculdade de Medicina da Universidade Federal de Pernambuco, do primeiro Serviço de Higiene Mental e Psicologia Clínica, com a finalidade de oferecer assistência psicológica e psiquiátrica aos estudantes universitários.

Com vistas a atenuar, pelo menos em parte, o problema do sofrimento psíquico na comunidade acadêmica, de maneira geral, na UFG, há o Programa Saudavelmente 2 , ligado à Pró-Reitoria de Assuntos Estudantis (PRAE) e que existe desde 2013. Conforme a apresentação do programa no site da universidade,

Há mais de 20 anos, a PROCOM deu início ao atendimento das questões de saúde mental da comunidade universitária da UFG, um trabalho que foi sendo construído ao longo desses anos, resultando no desenvolvimento do Programa Saudavelmente em 10 de abril de 2003. A Equipe de Saúde Mental do Programa atua no atendimento social, psiquiátrico e psicológico

\footnotetext{
${ }^{2}$ Disponível em: https://saudavelmente.prae.ufg.br/p/1062-apresentacao. Acesso em: 11 mar. 2019.
} 
de estudantes e servidores da UFG. Buscando uma compreensão dos processos que envolvem a saúde mental em seus diversos aspectos, a Equipe tem realizado um trabalho amplo, com ações diversificadas, como atendimentos individuais e em grupo, visitas a locais de trabalho, de estudo e domiciliares, reuniões entre profissionais de diferentes áreas e discussões interdisciplinares dos casos.

Além disso, a instituição realiza uma pesquisa intitulada "Saúde e Qualidade de Vida da Comunidade Universitária", cujos resultados serão a base para políticas de bem-estar voltadas à comunidade acadêmica de modo geral.

O Programa Saudavelmente tem como objetivos

[...] atendimento diferenciado e abrangente em saúde mental na UFG, que corresponda às necessidades de atenção em nível de prevenção, assistência e recuperação das intercorrências psíquicas e emocionais; Formar uma rede de atendimento, integrando os diversos serviços e produtos existentes no campo da assistência, estudos e pesquisas; Fazer o encaminhamento direcionado e qualificado para a rede de assistência externa; Desenvolver projetos que visem à promoção da saúde mental e melhoria da qualidade de vida da comunidade universitária. ${ }^{3}$

Trabalha-se com o método do acolhimento, desta forma, inicia-se o trabalho em uma reunião coletiva, no grupo, para o entendimento das demandas individuais. A partir daí, faz-se o planejamento dos atendimentos individuais ou em pequenos grupos. Há também um sistema de plantão para o atendimento das emergências. Este tem como base um único atendimento em caráter de urgência, cujo objetivo é atenuar e mitigar o sofrimento psíquico intenso, evitando consequências mais graves.

Segundo dados do programa ${ }^{4}$, em 2018 (de 2 de janeiro a 25 de outubro), procederam-se aos seguintes atendimentos: acupuntura - 604; atendimentos de plantão - 307; consultas psiquiátricas - 1.541; perícias - 234 processos e 422 pareceres; pessoas acolhidas - 411; prontuários ativos - 701; sessões de psicoterapia: 4.267; sessões de terapia em grupo: 201.

${ }^{3}$ Disponível em: https://saudavelmente.prae.ufg.br/p/1062-apresentacao. Acesso em: 11 mar. 2019.

${ }^{4}$ Disponível em: https://saudavelmente.prae.ufg.br/p/1062-apresentacao. Acesso em: 11 mar. 2019. 
Apesar de ser, portanto, um programa inovador no cenário das universidades públicas brasileiras, de ter efetividade e de contar com a legitimidade e o apreço da comunidade acadêmica, o problema do sofrimento psíquico está longe de ser adequadamente enfrentado em toda a sua complexidade. Para o próprio Programa Saudavelmente,

Diante da impossibilidade de atender a todos os membros da comunidade universitária, o Programa tem dado prioridade ao atendimento das populações mais vulneráveis, como aqueles que não possuem condições socioeconômicas para arcar com tratamentos privados. Por isso, durante o acolhimento (primeiro procedimento pelo qual passa a pessoa atendida) é feita a classificação de urgências e emergências e também uma avaliação socioeconômica. Dessa forma, o Programa garante que, pelo menos, os usuários em estado de urgência e os de baixa renda possam ser atendidos, buscando contribuir com a diminuição da evasão entre os estudantes e com a qualidade de vida dos mesmos e dos servidores. ${ }^{5}$

Ademais, vale notar que os estudantes indígenas, seja por desinformação, seja por demandas particulares, acabam não procurando costumeiramente o atendimento do Programa Saudavelmente, mas sim um relacionamento mais próximo com parentes, com os coletivos indígenas, com docentes conhecidos e com o centro de convivência do Programa UFGInclui.

Tal situação aponta, ademais, para a necessidade de um estudo mais aprofundado e específico sobre a saúde mental destas populações indígenas em trajetória acadêmica.

\section{VIOLÊNCIA EPISTÊMICA E SOFRIMENTO PSÍQUICO}

Há algumas outras ações interessantes elaboradas e efetivadas no âmbito da instituição, as quais atuam para aliviar o sofrimento psíquico dos estudantes indígenas.

Na UFG, com o acesso de indígenas, negros e negros quilombolas no Programa de Pós-Graduação em Antropologia Social, por exemplo, criou-se em 2018 uma nova disciplina, optativa, intitulada Epistemologias Indígenas e Negras. A ideia foi a de trazer para a discussão autores e autoras indígenas e negros/as,

\footnotetext{
${ }^{5}$ Disponível em: https://saudavelmente.prae.ufg.br/p/1062-apresentacao. Acesso em: 11 mar.
} 2019. 
entendidos com o mesmo status de autores não indígenas na produção de conhecimento antropológico. Desta forma, possibilitando aos discentes outros diálogos teóricos importantes para a elaboração de suas pesquisas e, ao mesmo tempo, propondo uma reformulação inicial da matriz curricular do programa, baseada na teoria clássica da antropologia e suas derivações, com base em uma matriz eurocêntrica de conhecimentos.

Conforme o programa da disciplina,

[...] o colegiado do PPGAS/UFG decidiu propor esta disciplina em função das dificuldades visíveis de adaptação dessxs alunxs ao sistema universitário que segue os padrões ocidentais e coloniais de ensino e de produção de pesquisa. Observamos também as dificuldades vividas por essxs alunxs em vários setores das vidas pessoais deles: solidão, permanência (moradia, bolsas de estudo, problemas de saúde), dificuldades com as normas linguísticas, com linguagem e leitura e escrita acadêmica. Em função dessas constatações, essa disciplina pretende acolher essxs alunxs, colocá-Ixs no coletivo da convivência entre cotistas, discutir problemas de adaptação na vida acadêmica, em primeiro lugar. Em segundo, nessa proposta, devemos incluir leituras produzidas por intelectuais indígenas e negrxs, buscando outras vertentes de produção de conhecimento, na contramão da ciência hegemônica ministrada nos programas de pós-graduação, propondo-se então a construção de novas bases epistêmicas para se pensar e produzir a universidade. (FERNANDES; RATTS; HERBETTA 2019 ).

É, entretanto, ainda muito pouco. Esse cenário torna-se ainda mais preocupante quando analisamos a situação de estudantes indígenas na universidade e percebemos que as políticas de inclusão e permanência desconsideram em grande medida os modos particulares de subjetivação indígena.

Entendemos, portanto, que parte do problema do sofrimento psíquico tem relação direta com os conflitos decorrentes da imposição de uma dinâmica monocultural, que invisibiliza, ignora e elimina outras formas de se entender o mundo, outras maneiras de se pensar e de se conceber a pessoa, outras práticas de saber e de viver.

Para Quintiliano (2019, p. 7), "nesta perspectiva, o que lemos na maioria dos casos enquanto pesquisa ainda é a objetificação dos corpos, a desumanização do sujeito das comunidades tradicionais, e na maioria das vezes, a usurpação dos saberes, que ao chegarem na academia tornam-se ciência do branco ou folclore". 
Ademais, em que pese o risco das classificações, os povos indígenas, ao chegarem à universidade, enfrentam, de acordo com Amaral e Baibich-Faria (2012, p. 819), o dilema do duplo pertencimento. Para os autores, "A construção da condição desse duplo pertencimento, árdua e em permanente estado de desequilibração, é devida tanto ao mérito próprio do acadêmico indígena quanto ao apoio familiar e à expectativa de sua comunidade de origem" (AMARAL; BAIBICH-FARIA, 2012, p. 819).

Em outras palavras, são sujeitos coletivos, fortemente vinculados às suas comunidades de origem e ao mesmo tempo passam a fazer parte do sistema acadêmico, fortemente homogeneizador, competitivo, monocultural, monoepistêmico e monolíngue.

No ambiente acadêmico, suas ontologias, seus conhecimentos e suas línguas não são sequer imaginados, pois para a maioria dos docentes dos cursos de graduação e pós-graduação essas dimensões no trato com os estudantes indígenas não são consideradas. Neste contexto, na maioria dos casos, o português é a segunda língua dos estudantes indígenas e, ao pertencerem a povos de tradição oral, possuem normalmente dificuldade em lidar com a escrita.

Vale lembrar que as línguas indígenas sofreram um violento processo de apagamento e desvalorização ao longo do processo colonizador.

No Brasil, as línguas indígenas foram sendo submetidas aos interesses do Estado e, quando muito, passado o período de proibição expressa do uso de outras línguas que não fosse o português, imposto pelo Diretório dos Índios elaborado pelo Marques de Pombal em 1755, foram submetidas a um bilinguismo de transição. Neste, as línguas indígenas seriam utilizadas como meio para a apreensão da cultura da sociedade envolvente. (NAZARENO, 2019, p. 302)

Nessa direção, para Tlostanova e Mignolo (2012, p. 245, tradução nossa), "a lógica da epistemologia ocidental e imperial consiste na efetivação de um metadiscurso que se autovalida desqualificando a diferença".

Outro aspecto bastante frequente no questionamento aos afazeres acadêmicos dos estudantes indígenas está relacionado à questão do tempo. Estudos recentes têm demonstrado que para alguns povos indígenas nem sequer existe a palavra tempo em seu vocabulário (SINHA et al., 2011; NAZARENO, 2017a; NAZARENO; 
ARAÚJO; GONÇALVES, 2019). No caso aqui tratado, diferentes temporalidades podem representar diferentes formas de lidar com as demandas acadêmicas.

Essas, entre outras questões, como a inseparabilidade entre cultura e natureza, apontam para a necessidade de a universidade passar por uma transformação, de modo a incluir outros regimes de conhecimento, e não apenas tomar como base a matriz de conhecimento ocidental, disciplinarizada. Para Lewis Gordon (2011), por exemplo, o regime disciplinar, dinâmica pedagógica e burocrática convencional na academia, aponta para um modo de produção e organização do conhecimento vinculado aos saberes ocidentais e à noção de modernidade, reforçando categorias como hierarquia e descontextualizando a realidade.

Nesse sentido, para o autor, a disciplina reduz os saberes ao ocidental e fortalece a noção de poder, baseada no que ele chama de fetichização do método, quando este é mais importante do que o conhecimento.

\section{TRANSFORMAÇÕES ESTRUTURAIS E OUTRAS SUBJETIVAÇÕES}

Conforme Quintiliano (2019, p. 8-9),

[...] para os indígenas e negros quilombolas que moram nas comunidades, a adaptação ao modo de vida acadêmico é cruel, devastador. Muitos dos estudantes não conseguem fazer essa transição e acabam desistindo de estudar. Principalmente aqueles estudantes que passaram a maior parte da vida escolar na comunidade. Em outros casos, estes estudantes em suas comunidades são reconhecidos por seus saberes, os quais dentro da universidade não são valorados.

Diante desse quadro preocupante de possibilidade de acesso, mas sem a garantia da permanência dos estudantes indígenas nos cursos de graduação e pós-graduação da UFG, o que gera sofrimento psíquico, o curso de Educação Intercultural da UFG, pertencente ao Núcleo Takinahakỹ de Formação Superior Indígena, surge como uma proposta que condensa resistência, afirmação e desobediência epistêmica ${ }^{6}$. E aponta, portanto, para soluções criativas e pertinentes para uma trajetória acadêmica mais saudável.

\footnotetext{
${ }^{6}$ O Curso de Licenciatura em Educação Intercultural da Universidade Federal de Goiás está dividido em quatro etapas práticas de atividades: Estudos Presenciais, nos meses de férias escolares e Estudos em Terras Indígenas. Durante todas as etapas de estudo, as atividades ocorrem semanalmente nos períodos matutino e vespertino (Cf. em NAZARENO, 2017b).
} 
Há outras experiências similares no país. Para Tassinari (2016, p. 50),

Enquanto a experiência da Licenciatura Intercultural do Sul da Mata Atlântica na UFSC conseguiu resultados expressivos, com a formatura de 85 dos 120 alunos matriculados, após quatro anos de curso, a PAA/UFSC [acesso por cotas] teve apenas um aluno formado, entre os 43 matriculados durante os sete anos de vigência.

Como foi observado, o curso criado em 2007 conta com quase 300 estudantes indígenas provenientes de 27 povos e de cinco estados da Federação. Seu objetivo fundamental é o de demonstrar como, diferentemente de outros espaços acadêmicos na UFG, os estudantes indígenas encontram no curso de Educação Intercultural um ambiente acolhedor, não somente do ponto de vista humanístico, como também político e epistêmico, favorável à afirmação de suas diferenças. Um ambiente acolhedor de outros modos de subjetivação.

No curso, os estudantes indígenas encontram um ambiente no qual podem compartilhar suas experiências de vida, suas histórias e, sobretudo podem ver respeitadas suas culturas. Com base nos temas contextuais, dinâmica pedagógica que se afasta da disciplinarização dos saberes, grande parte do conhecimento construído integra um movimento dialógico intercultural crítico em que não há sobreposição de saberes e tampouco de línguas. É bem verdade que a língua utilizada majoritariamente no curso é a que chamamos de português intercultural, entretanto as atividades acadêmicas que são realizadas enfatizam a valorização das línguas indígenas. É o que denominamos de bilinguismo epistêmico e intercultural.

Desse modo, os estudantes percebem como suas línguas e, por meio delas, seus saberes são valorizados, rompendo, assim, com a lógica da colonialidade do saber que subalternizou historicamente as línguas e os conhecimentos dos povos indígenas.

Um exemplo claro dessa metodologia decolonial é a possibilidade de construção de matrizes curriculares interepistêmicas não só no curso de Educação Intercultural, mas fundamentalmente nas escolas indígenas. Outro exemplo é o acolhimento por parte do fluxo do curso de momentos de luto coletivo, quando do falecimento de uma pessoa de determinada população. Nestes casos, todo o grupo é dispensado das aulas e o curso busca então modos alternativos para que se realizem as atividades acadêmicas. 
Sofrimento acadêmico e violência epistêmica: considerações iniciais sobre dores vividas em trajetórias acadêmicas indígenas

Note-se que, como funciona com base na pedagogia da alternância, com etapas alternadas entre Goiânia e as respectivas terras indígenas ${ }^{7}$, trata-se de maneira mais adequada as obrigações rituais, pessoais e profissionais dos discentes e, também, cuida-se do que nomeiam como saudade da casa e da família, fonte de grande sofrimento psíquico.

O curso busca igualmente transformar práticas individualistas e competitivas, observadas comumente no ambiente universitário, em práticas coletivas e solidárias, potencializando as redes e a noção de coletivo. Nesta direção, o comitê, que é constituído por discentes de um ou mais povos indígenas afins e docentes do Núcleo Takinahakỹ, é a base de organização das atividades do curso.

A dinâmica do comitê tem como objetivo produzir pesquisa/conhecimento de maneira coletiva acerca de temas relevantes para as comunidades, rompendo com pressupostos individualistas na produção e transmissão do conhecimento [...] O comitê é constituído igualmente a partir da participação dos sábios da comunidade. São eles que legitimam ações e políticas estabelecidas nos grupos, assim como determinam demandas e atividades importantes para o grupo. No âmbito do comitê observa-se claramente a interaprendizagem, cada população e sujeito contribuindo com o conhecimento do outro e se apropriando de novos saberes. ${ }^{8}$

Ao valorizar outros modos de subjetivação e de aprendizagem, o curso de Educação Intercultural da UFG tem propiciado a geração de fatores de proteção para os estudantes indígenas. Prova disso é o baixíssimo nível de evasão e de fracasso dos estudantes desse curso.

No mesmo curso, busca-se por fim romper com a imposição dos regimes disciplinares, cujo centro é a descontextualização dos saberes e a imposição de dicotomias ocidentais, tais como corpo/mente; teoria/prática; razão/emoção; sujeito/objeto. Desta forma, os indígenas discentes se transformam em sujeitos produtores de conhecimento, os quais, em rede com a universidade e suas comunidades, produzem uma nova base epistêmica, importante para se (re)pensar a escola, a universidade e a política.

\footnotetext{
${ }^{7}$ Durante o ano, ocorrem quatro etapas presenciais do curso de Educação Intercultural, duas na UFG, entre os meses de janeiro e fevereiro e entre julho e agosto, e duas etapas em terras indígenas, entre os meses de março e maio e entre agosto e novembro.

8 Projeto Pedagógico do Curso de Educação Intercultural da UFG (2006).
} 
Para Pimentel da Silva e Herbetta (2018, p. 13), "Esta nova base epistêmica busca transformar a marcante elitização da universidade brasileira, no caso da UFG".

De qualquer forma, a universidade precisa de criatividade para superar os obstáculos apresentados, os quais têm como base a violência epistêmica e, assim, criar estruturas e dinâmicas mais adequadas a outros sujeitos e a outros modos de subjetivação.

Para Damsokekwa (2015), entretanto,

[...] na prática as ações de efetivação desses direitos ainda são muito fragmentadas. É uma luta árdua para os conquistados serem reconhecidos e seus direitos garantidos como povos específicos. Ainda se trata de uma legislação "abstrata" em relação à realidade vivenciada pelos povos indígenas brasileiros que vivem hoje nos vários estados do território nacional.

\section{CONCLUSÃO}

Se conforme Andrade et al. (2016, p. 835), "em conclusão, o que se verifica, em relação ao atendimento psicoterapêutico ao estudante universitário, em geral, e aos dos cursos de Psicologia, em particular, é que a situação ainda demanda mais investigações", para Herbetta (2018, p. 331):

[...] apenas uma universidade que inclui concreta e efetivamente a diferença, desde um ponto de vista político e epistemológico, qual seja o de transformar suas dinâmicas estruturais levando em consideração também os modos próprios de se pensar o mundo de outros contingentes populacionais, culturalmente diferenciados, pode contribuir para uma sociedade mais tolerante, equilibrada e para um uso mais consciente do poder.

Neste sentido, no que se refere ao sofrimento psíquico entre populações indígenas em trajetórias acadêmicas, o qual se efetiva em abuso de álcool, retenção em disciplinas, evasão e tentativas de suicídio, pensamos que deve se notar um respeito pelos modos próprios de subjetivação destas pessoas.

As chamadas ciências ocidentais, entre elas a psicologia, deveriam considerar os modos próprios de subjetivação dos povos indígenas, tendo em vista uma relação de complementariedade entre saberes indígenas e não indígenas.

Neste cenário, para Pechincha (2018, p. 239), que trata do suicídio entre populações indígenas, 
Aproximamo-nos de um horizonte onde as narrativas mestras do "psíquico" têm que se render a evidências de que equivalentes simbólicos ou somáticos desta noção, que porventura seriam apreensíveis nos materiais disponíveis sobre os indígenas, não permitem concluir por uma equivalência etiológica aos moldes ocidentais quanto à aferição de enfermidade "mental", tampouco das condições garantidoras de bem-estar emocional e corporal, dicotomia que, ademais, não comparece nas ontologias indígenas.

De outra forma, para Andrade et al. (2016, p. 842-3), falando sobre discentes de maneira mais geral,

[...] estes sentimentos podem estar indicando uma situação de risco aumentado para o desenvolvimento de transtornos mentais nessa população de estudantes, o que sugere a necessidade de haver uma atenção mais cuidadosa, por parte da instituição universitária, com a consequente necessidade de discutir e propor medidas de manejo deste sofrimento como medida propiciadora de bem-estar no ambiente universitário.

Concluímos ressaltando a necessidade premente de políticas educacionais de inclusão e permanência para populações indígenas que tomem como base seus modos próprios de subjetivação. De outro modo, as ações esbarrarão na falta de entendimento de outras ontologias, da pluriversidade. Uma atitude política, intercultural crítica e decolonial torna-se imprescindível na busca do pluriversal, pois, como afirma Walter Mignolo (2007, p. 45),

A genealogia do pensamento decolonial é pluriversal (não universal). Assim, cada nó da rede desta genealogia é um ponto de partida e abertura que reintroduz idiomas, memórias, economias, organizações sociais, subjetividades, esplendores e misérias dos legados imperiais. Hoje, reclama-se um pensamento decolonial que articule genealogias espalhadas pelo planeta e ofereça "outras" modalidades econômicas, políticas, sociais e subjetivas. (tradução nossa)

A ideia de uma pluriversidade, portanto, que comporta distintos modos e práticas de subjetivação, não é só importante para a produção de conhecimento, mas para o bem-estar dos sujeitos que compõem a vida universitária. Entendemos ainda que produção de conhecimento e saúde psíquica não podem ser vistos separadamente; os saberes gerados em uma pluriversidade provavelmente terão a marca da sustentabilidade, tão necessária no mundo contemporâneo. 
Tratar de dores presentes em trajetórias acadêmicas indígenas na universidade, assim, é buscar um mundo mais equilibrado e justo. Acerca das diferentes formas de saber e existir, entre indígenas e não indígenas, o xamã Yanomami Davi Kopenawa assevera que os xamãs

[...] bebem yãkoana para poder contemplar suas imagens, em vez de reduzi-las a alinhamentos de traços tortuosos. Seu pensamento guarda as palavras do que viram sem ter de escrevê-las. Os brancos, ao contrário, não param de fixar seu olhar sobre os desenhos de suas falas colados em peles de papel e de fazê-los circular entre eles. Desse modo, estudam apenas seu próprio pensamento e, assim, só conhecem o que já está dentro deles mesmos. Mas suas peles de papel não falam nem pensam. Só ficam ali, inertes, com seus desenhos negros e suas mentiras. Prefiro de longe as nossas palavras! São elas que quero ouvir e continuar seguindo. Por manterem a mente cravada em seus próprios rastros, os brancos ignoram os dizeres distantes de outras gentes e lugares. (KOPENAWA; ALBERT, 2015, p. 455).

\section{REFERÊNCIAS}

AMARAL, Wagner Roberto; BAIBICH-FARIA, Tânia Maria. A presença dos estudantes indígenas nas universidades estaduais do Paraná: trajetórias e pertencimentos. Revista Brasileira de Estudos Pedagógicos, Brasília, v. 93, n. 235, p. 818-35, set./dez. 2012.

ANDRADE, Antonio dos Santos; ANTUNES, Natália Amaral; ZANOTO, Pedro Alves; TIRABOSCHI, Gabriel Arantes; VIANA, Paulo Vinícius Bachette Alves; CURILLA, Rafael Trebi. Vivências acadêmicas e sofrimento psíquico de estudantes de Psicologia. Psicologia: Ciência e Profissão, Brasília, v. 36, n. 4, p. 831-46, out./dez. 2016.

BERGAMASCHI, Maria Aparecida; DOEBBER, Michele Barcelos; BRITO, Patrícia Oliveira. Estudantes indígenas em universidades brasileiras: um estudo das políticas de acesso e permanência. Revista Brasileira de Estudos Pedagógicos, Brasília, v. 99, n. 251, p. 37-53, jan./abr. 2018.

CARVALHO, José Jorge de; SEGATO, Rita Laura. Uma proposta de cotas para estudantes negros na Universidade de Brasília. Brasília; [s.n.], 2002. Série Antropologia 314.

CHILISA, Bagele. Indigenous research methodologies. [S.I.]: SAGE Publications, 2012.

COLECTIVO SITUACIONES. Prólogo. Sobre el método. In: MTD SOLANO; COLECTIVO SITUACIONES. Hipotesis 891: Mas allá de los piquetes. Buenos Aires: Tinta Limón Ediciones, 2002. 
Sofrimento acadêmico e violência epistêmica: considerações iniciais sobre dores vividas em trajetórias acadêmicas indígenas

CRUZ, Felipe Sotto Maior. Indígenas antropólogos e o espetáculo da alteridade. Revista de Estudos e Pesquisas sobre as Américas, Brasília, v. 11, n. 2, p. 93-108, 2017.

DAMSOKEKWA, Ercivaldo. Os Direitos Humanos e a diversidade cultural a partir da experiência de um acadêmico indígena Akwê / Xerente, no mestrado em direitos humanos da UFG. In: SIMPÓSIO INTERNACIONAL DE CIÊNCIAS SOCIAIS, 4., Grupo de Trabalho: Universidade democrática? Impactos epistemológicos e político com a entrada de coletivos diferenciado promovido. Comunicação Oral. Goiânia: Faculdade de Ciências Sociais - UFG, 2015.

FERNANDES, Joana; RATTS, Alecssandro; HERBETTA, Alexandre. Programa da disciplina Epistemologias Indígenas e Negras. Programa de Pós-Graduação em Antropologia Social. Universidade Federal de Goiás, 2019.

GORDON, Lewis. Shifting the geography of reason in an age of disciplinary decadence. Transmodernity: Journal of Peripherical Cultural Production of the Luso-Hispanico World, Merced, v. 1, n. 2, p. 95-103, 2011.

HABER, Alejandro. Nometodología Payanesa: notas de metodología indisciplinada. Revista Chilena de Antropología, Santiago, Chile, n. 23, p. 9-49, 1o sem. 2011.

HERBETTA, Alexandre Ferraz. Políticas de inclusão e relações com a diferença: considerações sobre potencialidades, transformações e limites nas práticas de acesso e permanência da UFG. Horizonte Antropológico, Porto Alegre, ano 24, n. 50, p. 305-33, jan./abr. 2018.

INSTITUTO BRASILEIRO DE GEOGRAFIA E ESTATÍSTICA (IBGE). Censo Demográfico 2010 Características gerais dos indígenas: resultados do universo. Rio de Janeiro, 2010.

KOPENAWA, Davi; ALBERT, Bruce. A queda do céu: palavras de um xamã yanomami. Tradução de Beatriz Perrone-Moisés; prefácio de Eduardo Viveiros de Castro. 1. ed. São Paulo: Companhia das Letras, 2015.

KRAHÔ, Letícia Jôkàhkwyj. Pjê Ita jê kâm mã itê ampô kwy jakrepej: das possibilidades das narrativas na educação escolar do povo Krahô. 2019. Dissertação (Mestrado em Antropologia Social) - Faculdade de Ciências Sociais, Universidade Federal de Goiás, Goiânia, 2019.

MIGNOLO, Walter. El giro decolonial: reflexiones para una diversidad epistémica más allá del capitalismo global. Compiladores Santiago Castro-Gómez y Ramón Grosfoguel. Bogotá: Siglo del Hombre Editores: Universidad Central, Instituto de Estudios Sociales Contemporáneos: Pontificia Universidad Javeriana, Instituto Pensar, 2007. 
MUNDURUKU, Daniel A escrita e a autoria fortalecendo a identidade. 2017. Disponível em: https://pib.socioambiental.org/pt/A_escrita_e_a_autoria_fortalecendo_a_identidade. Acesso em: 12 mar. 2019.

NAZARENO, Elias. O Estado e as políticas linguísticas adotadas como estratégica na formação da nação brasileira a partir do século XVI. In: XAVIER, Lídia de Oliveira; AVILA, Carlos F. Domínguez; FONSECA, Vicente (Org.). A qualidade da democracia no Brasil: questões teóricas e metodológicas da pesquisa. 4. ed. Curitiba: CRV, 2019. v. 4, p. 299-317.

NAZARENO, Elias; ARAUJO, Ordália C. G.; PEREIRA, Tamiris M. G. Tempo, lugar e interculturalidade na perspectiva dos estudantes indígenas do curso de educação intercultural da UFG. Espaço Ameríndio, Porto Alegre, v. 13, n. 1, p. 87-113, jan./jun. 2019.

NAZARENO, Elias. História, tempo e lugar entre o povo indígena bero biawa mahãdu (javaé): a partir da interculturalidade crítica, da decolonialidade e do enfoque enactivo. In: OLIVEIRA, Marcos de Jesus (Org.). Direitos humanos e pluriversalidade: conexões temáticas. 1. ed. Curitiba: Prismas, 2017a. v. 1, p. 85-118.

NAZARENO, Elias. PIBID-diversidade: construção de bases epistemológicas na formação de professores indígenas. Crítica Educativa, Sorocaba, SP, v. 3, n. 2, Especial. p. 493-506, jan./jun. 2017b.

PECHINCHA, Monica. Aportes da etnografia sul-americanista ao entendimento dos suicídios indígenas: uma tentativa de síntese a partir de noções divergentes de "psique"/“alma". Anuário Antropológico, Brasília, v. 43, n. 1, p. 223-56, 2018.

PIMENTEL DA SILVA, Maria do Socorro; HERBETTA, Alexandre. Atualizando, juntando e esticando a universidade: considerações sobre a possibilidade de uma pluriversidade. PRACS: Revista Eletrônica de Humanidades do Curso de Ciências Sociais da UNIFAP, Macapá, AP, v. 11, n. 1, p. 11-26, jan./jun. 2018.

QUINTILIANO, Marta. Redes afroindígenoafetivas: uma autoetnografia sobre trajetórias, relações e tensões entre cotistas da pós-graduação stricto sensu e políticas de ações afirmativas na Universidade Federal de Goiás. 2019. Dissertação (Mestrado em Letras e Linguística) - Faculdade de Ciências Sociais, Universidade Federal de Goiás, Goiânia, 2019.

QUINTILIANO, Marta; JOKAKWYJ, Letícia. Epistemologias que curam. In:SSIMPÓSIO DA FACULDADE DE CIÊNCIAS SOCIAIS - DEMOCRACIA E DIREITOS HUMANOS: CRISES E CONQUISTAS, 4., 11 set. 2019, Goiânia. Comunicação Oral [...]. Goiânia: Faculdade de Ciências Sociais-UFG, 2019. 
Sofrimento acadêmico e violência epistêmica: considerações iniciais sobre dores vividas em trajetórias acadêmicas indígenas

SAMPAIO TUKANO, Daiara Hori Figueroa. Ukushe kiti niishe. Direito à memória e à verdade na perspectiva da educação cerimonial de quatro mestres indígenas. 2018. Dissertação (Mestrado em Direitos Humanos e Cidadania)- Universidade de Brasília (UnB), Brasília, 2018 .

SANTOS, Boaventura de Sousa. Da ideia de universidade à universidade de ideias. Revista Crítica de Ciências Sociais, Coimbra, n. 27/28, p. 11-62, jun. 1989.

SINHA, Chris; SINHA V. Silva; ZINKEN, Jörg; SAMPAIO, Wany. When time is not space: the social and linguistic construction of time intervals and temporal event relations in an Amazonian culture. Language and Cognition, v. 3, n. 1, p. 137-69, 2011.

TASSINARI, Antonela. Resultados e desafios da inclusão de estudantes indígenas pela política de ações afirmativas da UFSC. In: OLIVEIRA, Lucia Alberta Andrade de (Org.). A questão indígena na educação superior. Rio de Janeiro: FLACSO: GEA: UERJ: LPP, 2016. (Cadernos do GEA n. 10, jul./dez. 2016).

TLOSTANOVA, Madina V.; MIGNOLO, Walter D. Learning to unlearn: decolonial reflections from Eurasia and the Americas. Columbus: The Ohio State University Press, 2012.

\section{Sobre os autores:}

Alexandre Ferraz Herbetta: Doutor em Antropologia Social pela Pontifícia Universidade Católica de São Paulo (PUC-SP). Bolsista de Produtividade em Pesquisa do Conselho Nacional de Desenvolvimento Científico e Tecnológico (CNPq). Mestre em Antropologia Social e graduado em História pela Universidade Federal de Santa Catarina (UFSC). Professor associado da Universidade Federal de Goiás (UFG), e atua no Núcleo Takinahakỹ de Formação Superior Indígena e no Programa de Pós-Graduação em Antropologia Social. Tem experiência nas áreas de Antropologia, Educação e Interculturalidade, com ênfase em Metodologias Participativas, Processos de Descolonização e Etnologia Indígena. É vice-coordenador do Curso de Especialização em Educação Intercultural, vice-coordenador do Estágio Docência Supervisionado do Curso de Educação Intercultural e membro da Sociedad Latinoamericana de Estudios Interculturales. E-mail: alexandre_herbetta@yahoo.com.br, Orcid: http://orcid.org/0000-0003-1627-2177

Elias Nazareno: Pós-doutor pelo Programa de Pós-Graduação em Antropologia Social da Universidade de Brasília (UnB). Pós-doutor em Sociologia com bolsa do CNPq pela Universidade de Barcelona (UB). Doutor em Sociologia pela UB. Mestre em História pela UnB. Graduado em História pela Pontifícia Universidade 
Católica de Goiás (PUC-GO). Professor associado I do Programa de Pós-Graduação em História e do Curso de Educação Intercultural para Formação de Professores Indígenas da Universidade Federal de Goiás (UFG). Coordenador de Área do Programa Institucional de Bolsas de Iniciação à Docência - Pibid/UFG e coordenador do Grupo de Pesquisa do DGP/CNPq, História Indígena e História Ambiental: Interculturalidade Crítica e Decolonialidade da UFG. Pesquisador associado sênior vinculado ao Laboratório e Grupo de Estudos em Relações Interétnicas (LAGERI) do Departamento de Antropologia da UnB e professor visitante da Universidade de Jujuy, Argentina. Integrante do GT de História Ambiental da ANPUH. Tem experiência nas áreas de Etno-História, História, Sociologia e em Relações Internacionais, atuando principalmente nos seguintes temas: educação intercultural indígena, história indígena e educação quilombola. E-mail: eliasna@hotmail.com, Orcid: http://orcid.org/0000-0002-9689-9721

Recebido em 22 de julho de 2019.

Aprovado para publicação em 14 de outubro de 2019. 